\title{
IMPLEMENTATION OF ELECTRONIC MEDICAL RECORD IN HOSPITAL MANAGEMENT INFORMATION SYSTEM IN DEVELOPING COUNTRIES: A SYSTEMATIC REVIEW
}

\author{
Eka Purnama Dewi Ritonga, Dumilah Ayuningtyas
}

Hospital Administration Program, Faculty of Public of Health, Universitas Indonesia

\begin{abstract}
Background: The developing world faces health crises that threaten the lives of millions of people. Lack of health care infrastructure, shortage of well-trained health professionals, poor implementation of public health, and lack of access to health information are considered important barriers to scaling up. Different approaches have been implemented to overcome this gap. The implementation of e-health and especially electronic medical records may help improve and enhance healthcare in these countries. This study aimed to review systematically the implementation of elec- tronic medical record in hospital management information system in developing countries.

Subjects and Method: A systematic review was conducted by searching published articles from 2014 to 2019, from PubMed database. The keywords for this review were electronic medical record (EMR), implementation, hospital information system management, and developing country. The inclusion criteria were review, systematic review, clinical review and guidelines in English language, and maximum 5 years publications. After review process 5 articles were included in this review.

Results: The success factors of the implementation of EMR application were methods of using good data, human resources, effective management, infrastructure planning, and good technical implementation.

Conclusion: The success factors of EMR implementation are method of using good data, human resources, effective management, infrastructure planning and good technical implementation.
\end{abstract}

Keywords: electronic medical record, implementation, hospital information system management, developing country.

\section{Correspondence:}

Eka Purnama Dewi Ritonga. Hospital Administration Program, Faculty of Public of Health, Universitas Indonesia, Depok, West Java. Email: ekapurnamadewiritonga@yahoo.com. 